6

OPEN ACCESS

Citation: Millán M, Ordoñez CA, Parra MW, Caicedo Y, Padilla N, Pino LF, Rodríguez-Holguin F, Salcedo A, García A, Serna JJ, Herrera MA, Quintero L, Hernández F, Serna C, González HA. Hemodynamically unstable non-compressible penetrating torso trauma: a practical surgical approach. Colomb Méd (Cali), 2021; 52(2):e4024592 http://doi. org/10.25100/cm.v52i 2.4592

Received : 22 Oct 2020

Revised: 16 Jan 2021

Accepted : 05 Apr 2020

Published: 08 Apr 2021

Keywords:

Damage control surgery, hemodynamically unstable noncompressible penetrating torso trauma, REBOA, aortic occlusion, median sternotomy

Palabras clave:

Cirugía de control de daños, hemodinámicamente inestable, trauma penetrante del torso, REBOA, oclusión aórtica, estenotomía mediana

Copyright: (C) 2021 Universidad del Valle (c) (1) () $)$
REVIEW

\section{Hemodynamically unstable non-compressible penetrating torso trauma: a practical surgical approach}

\section{Guía práctica para el abordaje quirúrgico del trauma penetrante del torso en paciente hemodinámicamente inestable}

\author{
Mauricio Millán ${ }^{1,2}$ Carlos A. Ordoñez ${ }^{2,3,4}$ Michael W. Parra $^{(}$Yaset Caicedo $^{6}{ }^{(\mathbb{D}}$ Natalia \\ Padilla $^{6}$ Luis Fernando Pino ${ }^{4,7}$ Fernando Rodríguez-Holguín ${ }^{3}$ Alexander Salcedo ${ }^{2,3,4,7}$ \\ (1) Alberto García ${ }^{2,3,4}$ José Julián Serna ${ }^{2,3,4,} \mathbb{B}$ Mario Alain Herrera ${ }^{4,7}$ Laureano \\ Quintero ${ }^{4,8}$ Fabian Hernández $^{4,7}$ Carlos Serna $^{4}{ }^{\circledR}$ Adolfo González Hadad ${ }^{4,7,8}$ \\ ordonezcarlosa@gmail.com, carlos.ordonez@fvl.org.co \\ 1 Fundación Valle del Lili, Department of Surgery, Division of Transplant Surgery, Cali, \\ Colombia, 2 Universidad Icesi, Cali, Colombia. , 3 Fundación Valle del Lili, Department of \\ Surgery, Division of Trauma and Acute Care Surgery, Cali, Colombia., 4 Universidad del Valle, \\ Facultad de Salud, Escuela de Medicina, Department of Surgery, Division of Trauma and \\ Acute Care Surgery, Cali, Colombia. 5 Broward General Level I Trauma Center, Department \\ of Trauma Critical Care, Fort Lauderdale, FL, USA, 6 Fundación Valle del Lili, Centro de \\ Investigaciones Clínicas (CIC), Cali, Colombia, 7 Hospital Universitario del Valle, Department of \\ Surgery, Division of Trauma and Acute Care Surgery, Cali, Colombia. \\ 8 Centro Médico Imbanaco, Cali, Colombia.
}

\section{Abstract}

Penetrating torso trauma is the second leading cause of death following head injury. Traffic accidents, falls and overall blunt trauma are the most common mechanism of injuries in developed countries; whereas, penetrating trauma which includes gunshot and stabs wounds is more prevalent in developing countries due to ongoing violence and social unrest. Penetrating chest and abdominal trauma have high mortality rates at the scene of the incident when important structures such as the heart, great vessels, or liver are involved. Current controversies surround the optimal surgical approach of these cases including the use of an endovascular device such as the Resuscitative Endovascular Balloon Occlusion of the Aorta (REBOA) and the timing of additional imaging aids. This article aims to shed light on this subject based on the experience earned during the past 30 years in trauma critical care management of the severely injured patient. We have found that prioritizing the fact that the patient is hemodynamically unstable and obtaining early open or endovascular occlusion of the aorta to gain ground on avoiding the development of the lethal diamond is of utmost importance. Damage control surgery starts with choosing the right surgery of the right cavity in the right patient. For this purpose, we present a practical and simple guide on how to perform the surgical approach to penetrating torso trauma in a hemodynamically unstable patient. 
Conflicts of interest:

The authors declare that they have no conflict of interest

\section{Acknowledgments:}

For the illustrations and the design of the cover to the Anatomical Draftsman Fabian R. Cabrera P. Professor of the Design, Department of Faculty of Integrated Arts of the Universidad del Valle

Corresponding author:

Carlos A. Ordonez, MD, FACS.

Division of Trauma and Acute Care

Surgery, Department of Surgery.

Fundación Valle del Lili. Cali, Colombia; Division of Trauma and Acute Care

Surgery, Department of Surgery,

Universidad del Valle, Cali, Colombia;

Universidad Icesi, Cali, Colombia.

e-mail: ordonezcarlosa@gmail.com, carlos.ordonez@fvl.org.co

\section{Resumen}

El trauma penetrante del torso representa la segunda causa de muerte de origen traumático después del trauma craneoencefálico. En países desarrollados existe mayor prevalencia de trauma cerrado, asociado principalmente a accidentes de tránsito o caídas de grandes alturas. Mientas, que en países en vía de desarrollo el trauma penetrante es más prevalente con heridas por arma de fuego o por arma blanca asociado a la violencia y las desigualdades sociales. El trauma penetrante torácico y abdominal pueden presentar altas tasas de mortalidad en la escena del trauma si se comprometen estructuras importantes como el corazón, los grandes vasos o el hígado. Actualmente, existen controversias sobre el adecuado abordaje quirúrgico con la implementación o no de dispositivos endovasculares como el balón de resucitación endovascular de oclusión aórtica (Resuscitative Endovascular Balloon Oclussion of the Aorta - REBOA) y la realización de ayudas imagenológicas. El objetivo de este artículo es presentar el conocimiento sobre este tema, basado en la experiencia adquirida durante los últimos 30 años con el manejo del trauma, cirugía general y cuidado crítico. Sostenemos que en un paciente hemodinámicamente inestable se debe realizar una temprana oclusión aórtica endovascular o abierta con el objetivo de evitar el desarrollo o propagación del rombo de la muerte. Con este propósito, presentamos una guía práctica y sencilla sobre el abordaje quirúrgico del paciente hemodinámicamente inestable con trauma penetrante del torso.

\section{Remark}

\section{1) Why was this study conducted?}

Current controversies surround the optimal surgical approach of penetrating and blunt trauma cases are topic of discussion including the use of an endovascular device such as the Resuscitative Endovascular Balloon Occlusion of the Aorta (REBOA) and the timing of additional imaging aids

\section{2) What were the most relevant results of the study?}

We have found that prioritizing the fact that the patient is hemodynamically unstable and obtaining early open or endovascular occlusion of the aorta to gain ground on avoiding the development of the lethal diamond is of utmost importance. Damage control surgery starts with choosing the right surgery of the right cavity in the right patient

\section{3) What do these results contribute?}

We present a practical and simple guide on how to perform the surgical approach to penetrating torso trauma in a hemodynamically unstable patient. 


\section{Introduction}

Penetrating torso trauma is the second leading cause of death following head injury ${ }^{1,2}$. Traffic accidents, falls and overall blunt trauma are the most common mechanism of injuries in developed countries; whereas, penetrating trauma which includes gunshot and stabs wounds is more prevalent in developing countries due to ongoing violence and social unrest ${ }^{3,4}$. Penetrating chest and abdominal trauma have high mortality rates at the scene of the incident when important structures such as the heart, great vessels, or liver are involved ${ }^{5,6}$. Current controversies surround the optimal surgical approach of these cases including the use of an endovascular device such as the Resuscitative Endovascular Balloon Occlusion of the Aorta (REBOA) and the timing of additional imaging aids ${ }^{7-9}$. The aim of this article is to shed light on this subject based on the experience earned during the past 30 years in trauma critical care management of the severely injured patient from the Trauma and Emergency Surgery Group (CTE) of Cali, Colombia which is made up of experts from the University Hospital del Valle "Evaristo García" and University Hospital Fundación Valle del Lili, the Universidad del Valle and Universidad Icesi, the Asociación Colombiana de Cirugía, the Pan-American Trauma Society and the collaboration of international specialists of the United States of America, Europe, Japan, South Africa, and Latin America.

\section{Initial Approach}

Initial management must be directed towards the stabilization of the patient with non-compressible torso hemorrhage according to Advanced Trauma Life Support (ATLS) $^{\circ}$ guidelines and following damage control resuscitation principles ${ }^{10}$. Upon arrival, the choice between immediate surgical exploration or further imaging studies is dependent on the hemodynamic status of the patient. If the patient is hemodynamically stable or a transient responder, additional imaging studies can be performed including an Extended Focused Assessment with Sonography for Trauma (E-FAST) and/or computed tomography to determine the extent of the injuries ${ }^{11}$. However, patients with hemodynamic instability (sustained systolic blood pressure (SBP) $(90 \mathrm{~mm} \mathrm{Hg}$ ) should be transferred immediately to the operating room for hemorrhage control ${ }^{12}$. This procedure demands full contemplation of the mechanism and trajectory of the injury and early endovascular or open occlusion of the aorta to ensure vital organ perfusion before opening the compromised body cavity.

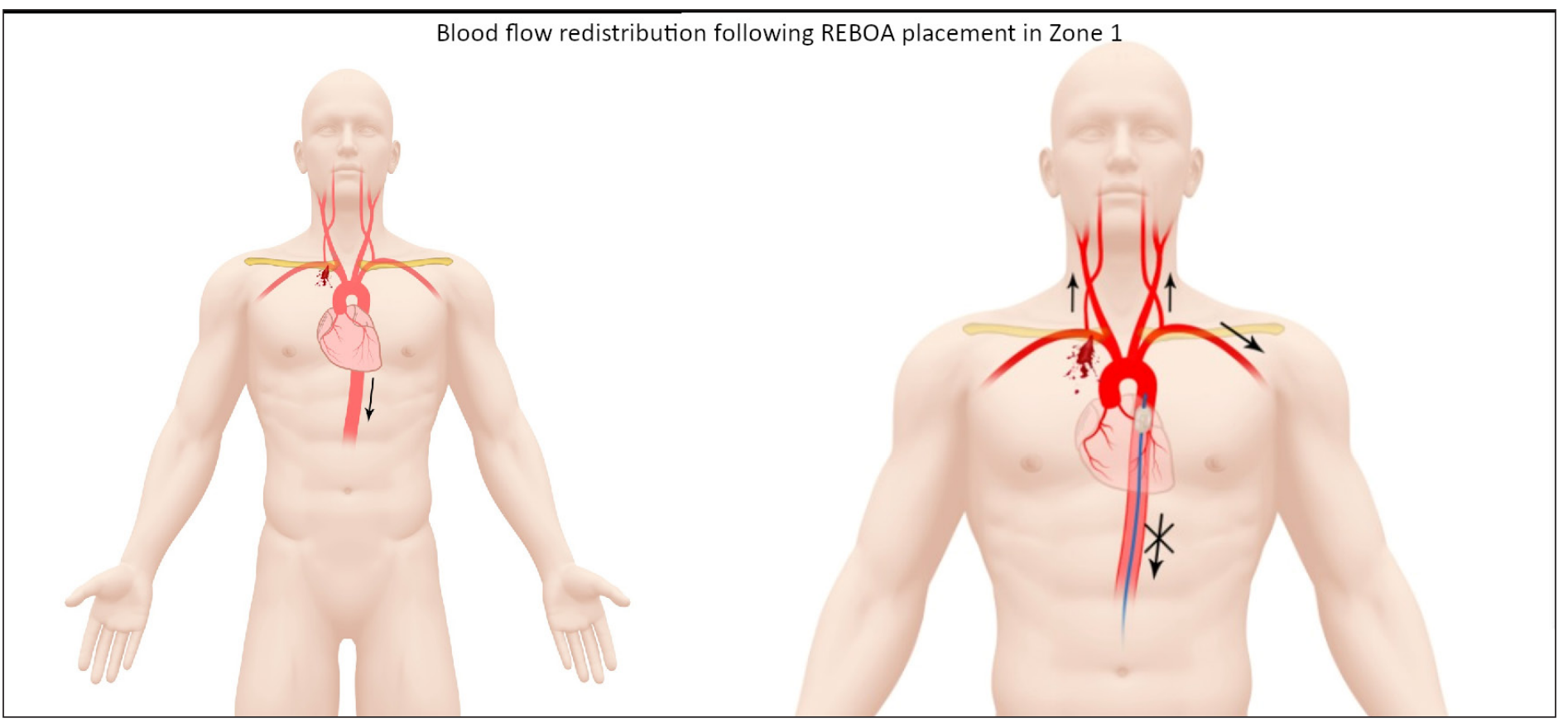

Figure 1. Blood flow redistribution following REBOA placement in Zone 1 


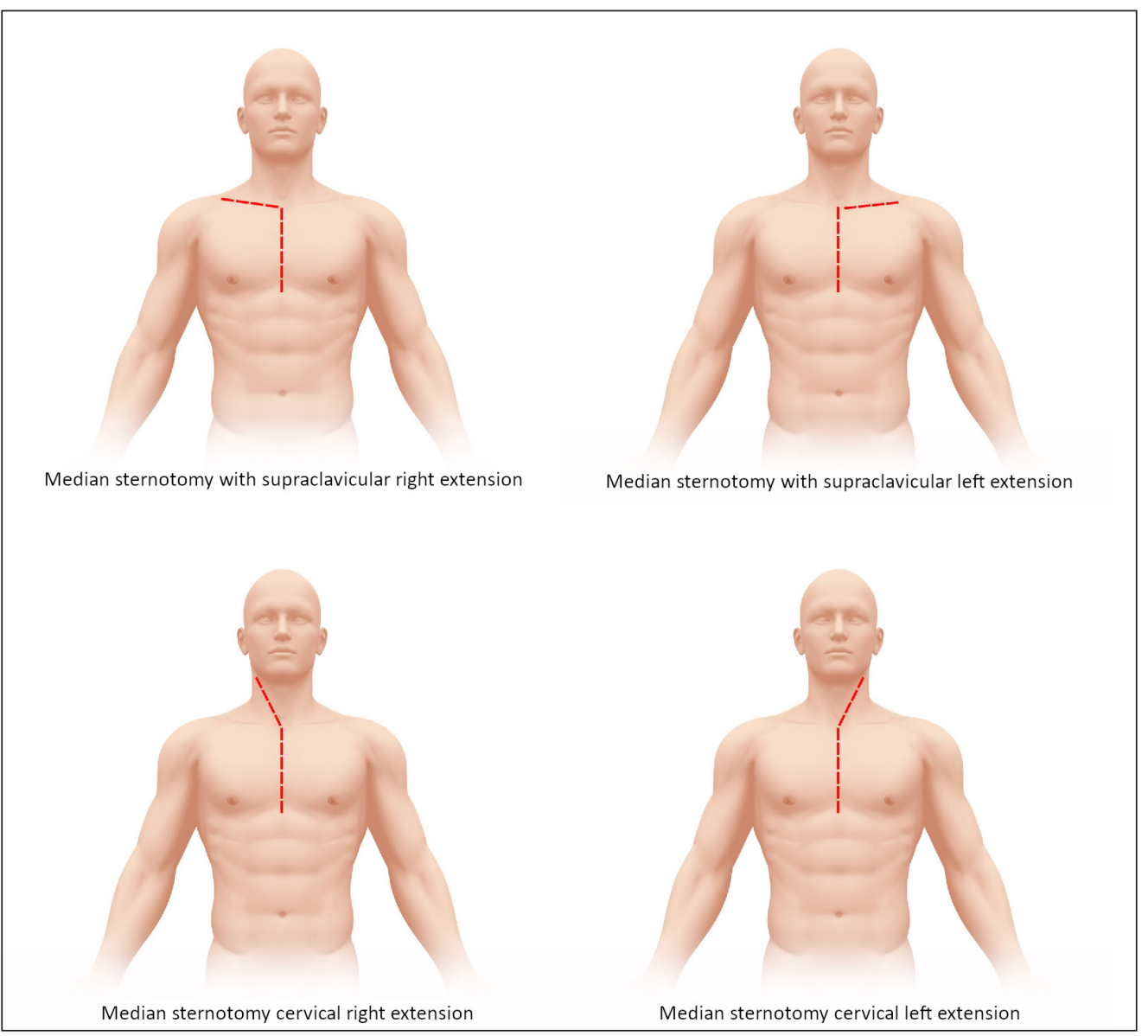

Figure 2A. Median Sternotomy with Supra-clavicular Right or Left Extension; 2B. Median Sternotomy with Cervical Right or Left Extension

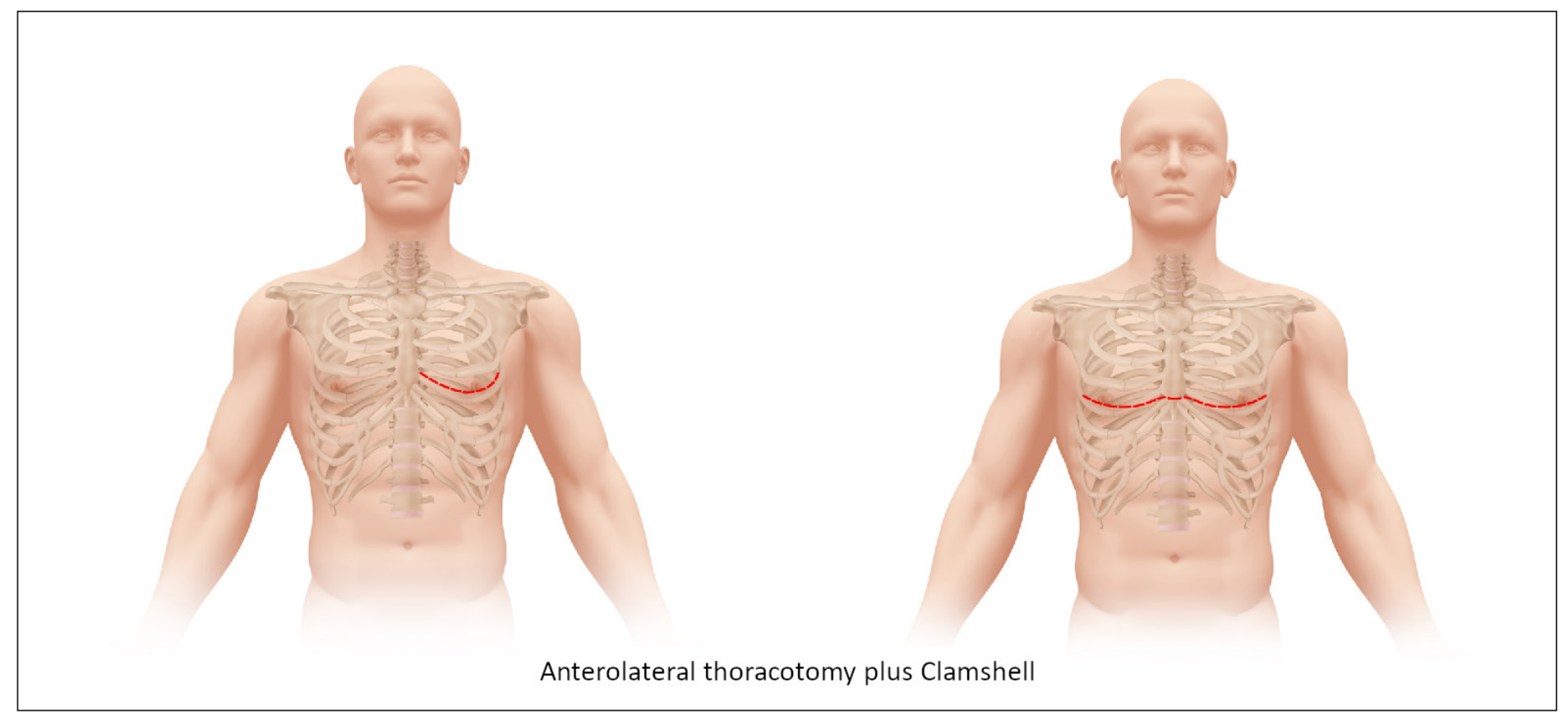

Figure 3. Antero-lateral Thoracotomy plus Clamshell 


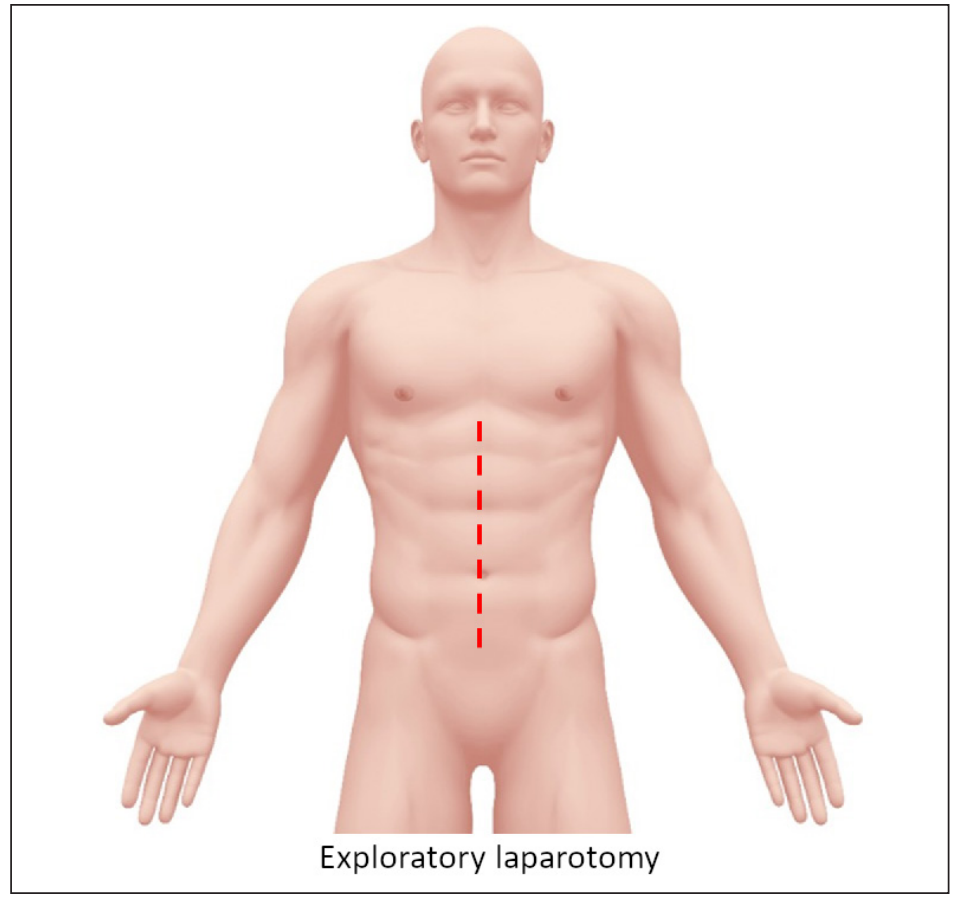

Figure 4. Exploratory Laparotomy

\section{Surgical Management}

Based on our experience, we propose a new stepwise approach to the management of hemodynamically unstable penetrating torso trauma:

\section{Scenario I: Hemodynamically Unstable Patient with SBP between 70 - $90 \mathrm{~mm} \mathrm{Hg}$}

- $\quad$ STEP 1: Attention should be directed towards identifying all immediate life-threatening injuries following the ABCDE mnemonic of ATLS (chest x-ray and E-FAST exam). Both a common femoral vein and artery lines are placed for intravenous access, blood pressure monitoring and the initiation of an aggressive damage control resuscitation.

- STEP 2: If the patient is hemodynamically stable or a transient responder, computed tomography should be performed to determine the extent of the damage and the presence of any other associated injuries ${ }^{11}$. According to the computed tomography findings, the patient can undergo either non-operative management versus open, endovascular and/or combined hybrid repair of the injuries. If the patient does not respond to initial resuscitation maneuvers, then:

\section{Scenario II: Hemodynamically Unstable Patient with SBP $<70$ mm Hg}

- $\quad$ STEP 3: The patient should have their common femoral arterial line changed over a guidewire to a femoral sheath, followed by placement of a REBOA in Zone 1, placed either in the operating or emergency room. The REBOA becomes an important resuscitative tool that ultimately prevents hemodynamic collapse while at the same time maintains coronary and cerebral perfusion. Simultaneously, the institution's massive transfusion protocol should be activated (Figure 1).

- STEP 4: Surgical approach according to anatomical areas with prior REBOA placement 


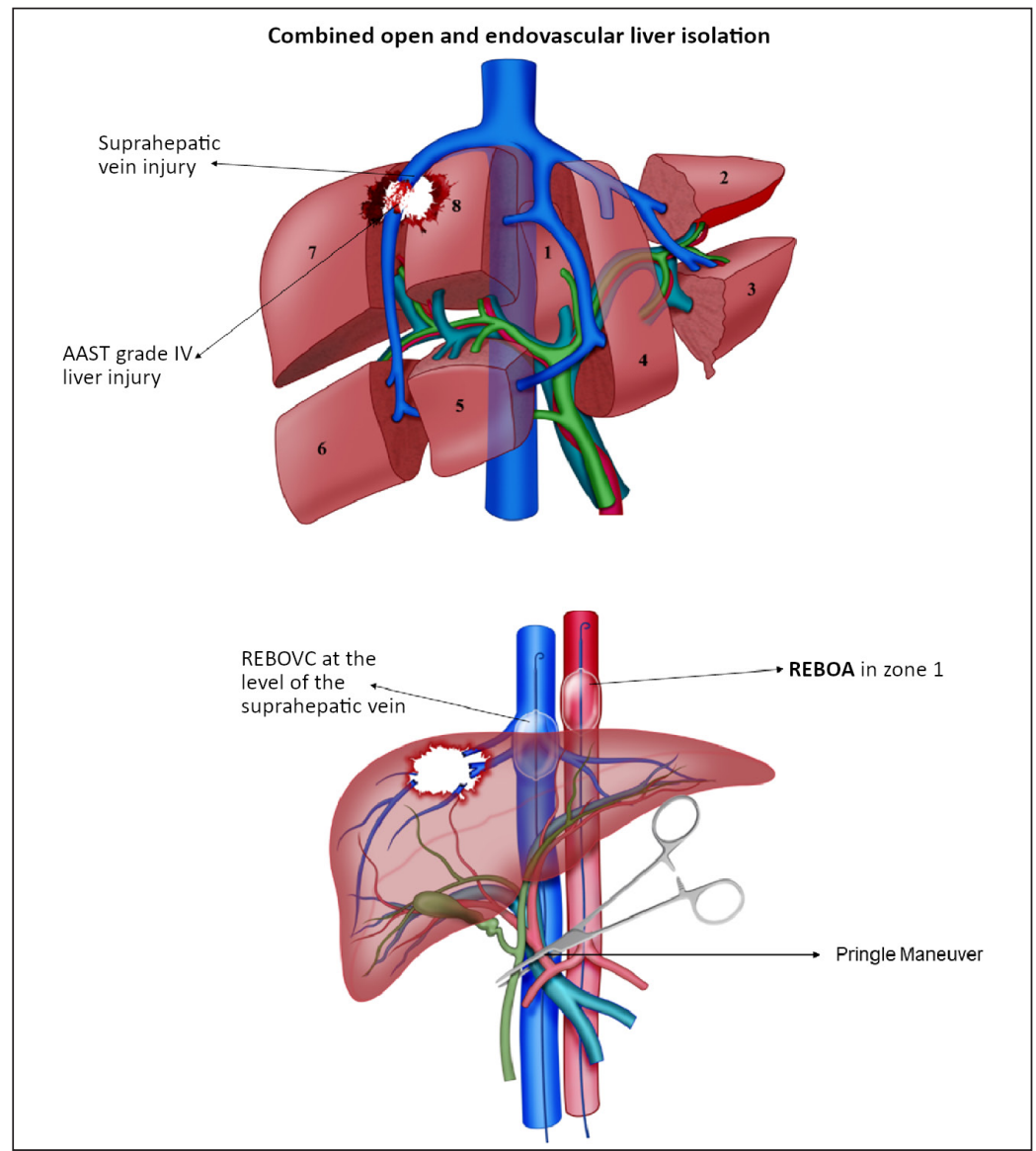

Figure 5A. Complex Penetrating Liver Injury AAST Grade III-V; 5B. Combined Open and Endovascular Liver Isolation with Pringle Maneuver, REBOA (resuscitative endovascular balloon occlusion of the aorta) and REBOVC (Resuscitative balloon occlusion of the inferior vena cava)

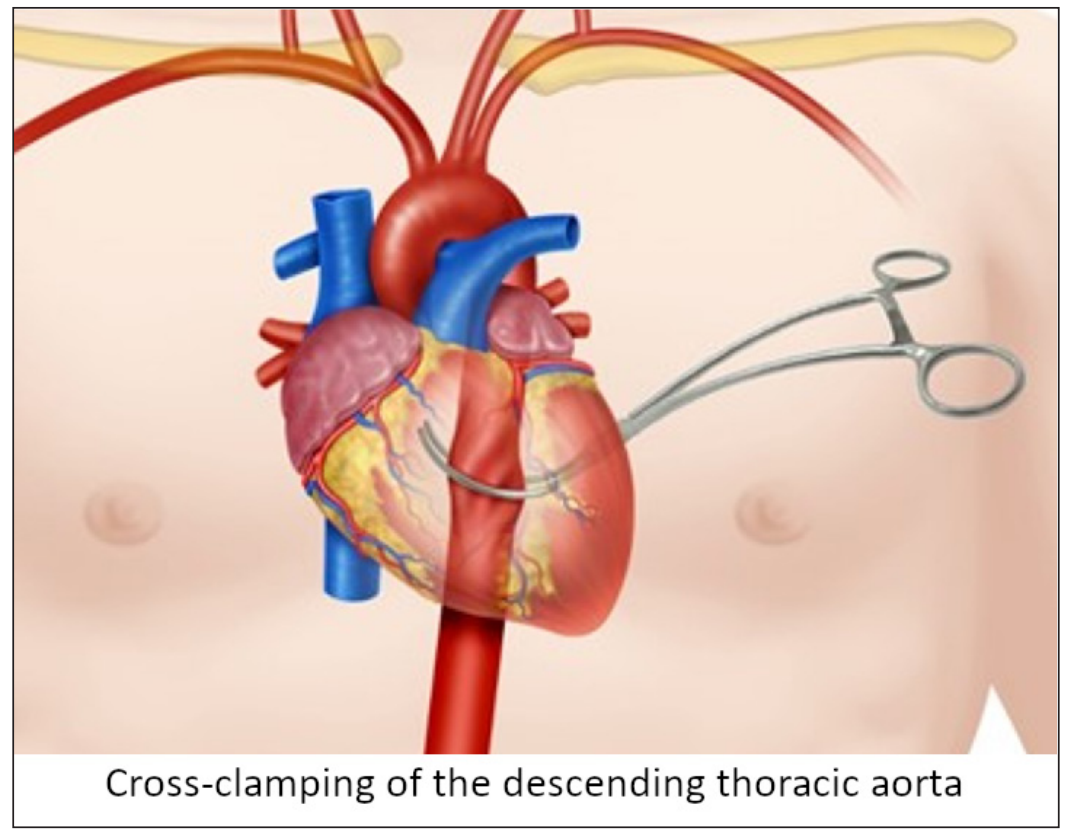

Figure 6. Cross-Clamping of the Descending Thoracic Aorta 
Upper Torso Upper Mediastinum: A median sternotomy should be performed for the following suspected injuries: heart, pulmonary hilum, aortic arch and ascending aorta. The

injury trajectory should be taken into account to decide whether to perform a right or left supra-clavicular or cervical extension (for thoracic outlet great vessel involvement: subclavian/ carotid/innominate) (Figure 2A/2B). An anterolateral thoracotomy is not recommended for these types of injuries because access to these structures is limited.

Lower Mediastinum: Also, central lower mediastinal injuries can be managed ideally by a median sternotomy; but lateralized injuries can be accessed via a left or right anterolateral thoracotomy, respectively. Either one of these incisions can be extended to the contralateral side (clamshell and reverse clamshell) when necessary (Figure 3).

Lower Torso Left Thoraco-Abdominal Area: An exploratory laparotomy plus a left chest tube should be performed. If the chest tube drainage is $>1500 \mathrm{cc}$, then a left anterolateral thoracotomy should follow to control ongoing surgical hemorrhage emerging from the chest cavity (Figure 4).

Right Thoraco-Abdominal Area: An associated liver injury should be suspected, and an exploratory laparotomy should be performed followed by packing, Pringle Maneuver and selective vessel ligation. For complex injuries, Grades III-V according to the American Association for the Surgery of Trauma (AAST) a combined open and endovascular liver isolation should be performed, which include a Pringle Maneuver, the placement of a REBOA in Zone 1 and a Resuscitative Endovascular Balloon Occlusion of the Vena Cava (REBOVC) ${ }^{13}$. A right chest tube should also be placed to manage potential ipsilateral chest involvement (Figure $5 \mathrm{~A} / 5 \mathrm{~B}$ ).

Abdominal \& Pelvic Area: An exploratory laparotomy should be performed to achieve immediate control of all ongoing surgical bleeding. In pelvic bleeding cases, the REBOA can be repositioned from Zone 1 to Zone 3 to diminish possible mesenteric ischemic time while achieving proximal control of hemorrhage ${ }^{14,15}$.

- STEP 5: Surgical approach according to anatomical areas without a REBOA

Upper Torso Upper Mediastinum: Following median sternotomy, direct digital control of the bleeding is obtained and the left mediastinal pleura is opened with medial rotation of the left lung and the descending thoracic aorta is cross-clamped using a straight vascular instrument.

Lower Mediastinum: If a median sternotomy was performed then the aorta is cross-clamped as above but if a left anterolateral thoracotomy was performed then the lung is mobilized superiorly. The descending thoracic aorta is cross-clamped with a straight vascular instrument. If the initial incision was a right anterolateral thoracotomy then a separate left anterolateral thoracotomy must be performed or the initial incision extended through the sternum as a reverse clamshell to access the descending thoracic aorta (Figure 6).

Lower Torso Left/Right Thoraco-Abdominal Area: Via the exploratory laparotomy, aortic occlusion can be achieved by direct manual pressure or cross-clamping of the supra celiac portion. A left anterolateral thoracotomy with cross-clamping of the descending thoracic aorta can be performed in cases of access difficulties.

Abdominal \& Pelvic Area: Aortic occlusion can be achieved by direct manual pressure or cross-clamping of the supra celiac portion for a Zone 1 occlusion or above the iliac bifurcation for a Zone 3 occlusion. A left anterolateral thoracotomy with cross-clamping of the descending thoracic aorta can be performed in cases of access difficulties. 


\section{Scenario III: Patient in cardiac arrest}

\section{- STEP 6:}

A. Initiate cardiopulmonary resuscitation, activate your massive transfusion protocol, perform a left anterolateral thoracotomy, direct cross-clamping of the descending thoracic aorta, open the pericardium and perform direct cardiac massage. If the patient recovers spontaneous circulation, damage control surgery principles should follow to control all ongoing surgical hemorrhage.

B. Initiate cardiopulmonary resuscitation, activate your massive transfusion protocol, place a REBOA in Zone 1, perform a median sternotomy, open the pericardium and perform direct cardiac massage. If the patient recovers spontaneous circulation, damage control surgery principles should follow to control all ongoing surgical hemorrhage.

\section{Conclusion}

The surgical approach to penetrating torso trauma depends on the mechanism, trajectory and most of all the hemodynamic status of the patient. Prioritizing the fact that the patient is hemodynamically unstable and obtaining early open or endovascular occlusion of the aorta to gain ground in avoiding the development of the lethal diamond is of utmost importance. Damage control surgery starts with choosing the right surgery of the right cavity in the right patient. For this purpose, we present a practical and simple guide on how to perform the surgical approach to penetrating torso trauma in a hemodynamically unstable patient.

\section{References}

1. Eckert KL. Penetrating and blunt abdominal trauma. Crit Care Nurs Q. 2005; 28:41-59. doi: 10.1097/00002727-200501000-00005.

2. Orlas CP, Herrera-Escobar JP, Zogg CK, Serna JJ, Meléndez JJ, Gómez A, et al. Chest Trauma Outcomes: Public Versus Private Level I Trauma Centers. World J Surg. 2020; 44(6):1824-1834. doi: 10.1007/s00268-020-05400-w.

3. Ordoñez CA, Manzano-Nunez R, Naranjo MP, Foianini E, Cevallos C, Londoño MA, et al. Casualties of peace: An analysis of casualties admitted to the intensive care unit during the negotiation of the comprehensive Colombian process of peace. World J Emerg Surg. 2018;13:2. doi: 10.1186/s13017-017-0161-2.

4. Pinedo-Onofre JA, Guevara-Torres L, Sánchez-Aguilar JM. Penetrating abdominal trauma. Cir Cir. 2006;74:431-42. doi: 10.1097/00005373-198703000-00004.

5. Beitner MM, Suh N, Dowling R, Miller JA. Penetrating liver injury managed with a combination of balloon tamponade and venous stenting. A case report and literature review. Injury. 2012;43:119-22. doi: 10.1016/j. injury.2011.08.028.

6. Kobayashi LM, Costantini TW, Hamel MG, Dierksheide JE, Coimbra R. Abdominal vascular trauma. Trauma Surg Acute Care Open. 2016; 1(1):e000015. doi: 10.1136/tsaco-2016-000015.

7. Segalini E, Di Donato L, Birindelli A, Piccinini A, Casati A, Coniglio C, et al. Outcomes and indications for emergency thoracotomy after adoption of a more liberal policy in a western European level 1 trauma centre: 8-year experience. Updates Surg. 2019;71:121-7. doi: 10.1007/s13304-018-0607-4.

8. Ordoñez CA, Parra MW, Manzano-Nunez R, Herrera-Escobar JP, Serna JJ, Rodriguez Ossa P, et al. Intraoperative combination of resuscitative endovascular balloon occlusion of the aorta and a median sternotomy in hemodynamically unstable patients with penetrating chest trauma: Is this feasible? J Trauma Acute Care Surg. 2018;84:752-7. doi: 10.1097/TA.0000000000001807. 
9. Ordoñez CA, Herrera-Escobar JP, Parra MW, Rodriguez-Ossa PA, Mejia DA, Sanchez Al, et al. Computed tomography in hemodynamically unstable severely injured blunt and penetrating trauma patients. J Trauma Acute Care Surg. 2016;80:597-603. doi: 10.1097/TA.0000000000000975.

10. The Comittee on Trauma. Advanced Trauma Life Support. Student Course Manual. American College of Surgeon. 10th Edition; 2018. doi: 10.1111/j.1365-2044.1993.tb07026.x.

11. Ordoñez CA, Parra MW, Holguín A, García C, Guzmán-Rodríguez M, Padilla N, et al. Whole-body computed tomography is safe, effective and efficient in the severely injured hemodynamically unstable trauma patient. Colomb Med (Cali). 2020; 51(4): e4054362. doi: 10.25100/cm.v51i4.4362.

12. Ordoñez CA, Rodríguez F, Orlas CP, Parra MW, Caicedo Y, Guzmán M, et al. The critical threshold value of systolic blood pressure for aortic occlusion in trauma patients in profound hemorrhagic shock. J Trauma Acute Care Surg. 2020;89:1107-13. doi: 10.1097/TA.0000000000002935.

13. Ordoñez CA, Parra M, Millan M, Caicedo Y, Guzman M, Padilla N, et al. Damage Control in Penetrating Liver Trauma: Fear of the Unknown. Colomb Med (Cali) 2020;51(4): e4134365. doi: 10.25100/cm.v51i4.4365.

14. Ordoñez CA, Parra M, Caicedo Y, Padilla N, Rodriguez F, Serna JJ, et al. REBOA as a New Damage Control Component in Hemodynamically Unstable NTCH patients. Colomb Med (Cali). 2020. 51(4): e4064506. Doi: 10.25100/cm.v51i4.45060rdoñez

15. Ordoñez CA, Rodríguez F, Parra M, Herrera JP, Guzmán-Rodríguez M, Orlas C, et al. Resuscitative endovascular balloon of the aorta is feasible in penetrating chest trauma with major hemorrhage: Proposal of a new institutional deployment algorithm. J Trauma Acute Care Surg. 2020;89:311-9. doi: 10.1097/ ta.0000000000002773. 